\title{
MESA DE PASSAR: UMA NOVA PROPOSTA ERGONÔMICA
}

\author{
Andreia Jardim Colvero \\ Universitário Franciscano \\ andreiacolvero@gmail.com \\ Edu Grieco Mazzini Junior \\ Centro Universitário Franciscano \\ edumazzini@hotmail.com
}

Resumo: Neste artigo se apresenta um estudo sobre o desgaste físico e mental sofrido pelos usuários ao executarem a tarefa de passar roupas, causado pela ausência de adequações ergonômicas nas mesas de passar existentes no mercado atual. Além disso, a maneira de se executar essa tarefa, com o acúmulo de grandes quantidades de peças de roupas, costuma resultar em lesões causadas por esforços repetitivos (LER). O estudo tem como base a metodologia de Löbach (2001) e a consulta a materiais bibliográficos sobre ato de passar roupas, mobiliário, design, semiótica, materiais, ergonomia e aspectos sociológicos. A análise comparativa realizada sobre os modelos de mesas existentes resultou em uma solução de design que proporciona ao usuário maior conforto e bemestar, principalmente com relação à segurança e à ergonomia. O projeto foi baseado no mobiliário já existente no mercado e, a fim de melhorar a qualidade de vida das pessoas que necessitam exercer essa atividade doméstica, foi aprimorado a partir das necessidades e das reclamações dos usuários. A partir das informações coletadas, desenvolveram-se alternativas até a definição da forma mais adequada aos requisitos e que correspondesse às necessidades evidenciadas pelo público-alvo, desde a escolha do material utilizado até o acabamento do mobiliário, visando ao máximo evitar o desconforto sofrido pelos usuários ao exercerem a tarefa. Finalmente definiu-se o projeto que melhor compunha um ambiente e se integrava ao restante do mobiliário, sem aparentar ser apenas um móvel específico para a atividade, mas mostrando-se como um móvel versátil e contemporâneo utilizado para facilitar o trabalho executado.

Palavras-chave: conforto, bem-estar, segurança, ergonomia.

\begin{abstract}
This paper presents an analysis of physical and mental fatigue experienced by users while ironing. These can be caused by the lack of an adequate ergonomic design in the state-of-the-art dedicated furniture. Besides, this domestic activity is usually performed for a while with a large amount of pieces, which can result in repetitive strain injury (RSI). The project is based on Löbach's scientific methodology (2001) and further research on actual literature about the ironing activity, specific furniture,
\end{abstract}


design, semiotics, materials, ergonomy and sociological aspects. The stateof-the-art analysis has led to a design solution that would provide more comfort and well-being to the user, mainly regarding safety and ergonomy. The project has been based on the already available options on-market and, seeking for a life quality improvement, it was enhanced according to users' needs and claims. Therefore, several alternatives have been developed until the most suitable version was selected. This choice has been made regarding the highlighted needs from the target audience, since the manufacture material up to furniture finishing, always seeking for the discomfort avoidance from the users while ironing. Finally, the chosen alternative was the one that best fitted the ambiance and best harmonized with the rest of the furniture, without looking as a specific ironing board or table, but instead a versatile and contemporary piece of furniture used to facilitate domestic work.

Keywords: ironing board, comfort, well-being, safety, ergonomy.

\section{INTRODUÇÃO}

Passar roupas é uma atividade cotidiana a qual traz desgaste físico e mental, além de ocupar boa parte do tempo das pessoas. Embora seja uma atividade comum, segundo o Ministério da Saúde (2009), ainda nos dias de hoje e apesar da presente evolução tecnológica, é muito grande o número de pessoas que sofrem com doenças causadas por esforços repetitivos, ocasionados, inclusive, pelo ato de passar roupas.

Ainda de acordo com o Ministério da Saúde (2009), o uso excessivo do computador, a lavagem manual de roupas e o ato de passar um número elevado de roupas podem causar desgaste por esforços repetitivos aos usuários. Esse esforço ainda é somado a locais inadequados de trabalho, assim como às medidas inapropriadas de mesas de passar.

Atualmente, devido à rotina diária dos usuários, atribulados de trabalho dentro e fora de casa, buscam-se soluções que facilitem seu dia a dia, minimizando o desgaste físico e emocional da execução de tarefas, melhorando a sua qualidade de vida, a fim de lhes proporcionar bem-estar e conforto. Nesse sentido, este estudo busca desenvolver um móvel doméstico, no caso, uma mesa de passar roupas, que ofereça adequação ergonômica, levando em conta os problemas encontrados nos produtos similares existentes no mercado e as necessidades que os usuários possuem.

Para este propósito, foi feita uma pesquisa com o público-alvo, assim um estudo deste produto e de suas restrições. A pesquisa visa entender o problema na sua totalidade, buscando minimizar ao máximo possível o desgaste físico do usuário e ampliar a funcionalidade deste produto.

O desenvolvimento deste projeto justifica-se pela necessidade das pessoas de sentirem conforto ao exercerem atividades domésticas como o ato de passar roupas. Sendo assim, objetiva-se executar um reestudo de um móvel voltado a este ato, que além de oferecer bem-estar ao usuário, agregue qualidade e função ao produto.

Nos resultados de pesquisas desenvolvidas junto ao público-alvo destacou-se a percepção dos usuários de que a atividade de passar roupas é desgastante e cansativa, 
levando, em geral, ao estresse e à fadiga. Atrelado a isso, deve-se levar em conta a frequência dessa atividade, assim como a quantidade de roupas passadas a cada vez. Esta soma de atividades erradas ao manuseio de produtos inadequados resulta em desgaste físico e muscular.

Muitas vezes, o fato de não haver um local adequado para essa atividade prejudica a saúde do usuário, causando-lhe desconforto e mal-estar, transformando um ato rotineiro em um transtorno doméstico e tornando esse usuário propenso a doenças musculares e fisiopatológicas. Portanto, o desenvolvimento deste projeto justifica-se pela adequação do produto ao uso ergonomicamente correto, trazendo maior conforto e bem-estar ao usuário.

\section{ERGONOMIA}

Segundo Lida (2005), a ergonomia é o estudo da adaptação do trabalho ao homem. Para o autor, a palavra trabalho tem um significado amplo, pois compreende não apenas máquinas e equipamentos utilizados para transformar materiais, como também o contexto em que ocorre a relação entre o homem e seu trabalho, para que se produzam os resultados desejados.

A ergonomia tem como objetivo a melhor adequação ou adaptação do objeto para os seres vivos em geral, destacando-se no que diz respeito à segurança, ao conforto e à eficácia de uso ou de operação dos objetos, particularmente nas atividades ou tarefas humanas (GOMES FILHO, 2003). Já para Falzon (2007), a ergonomia é a aplicação de conhecimentos científicos relativos ao homem na intenção de se obter o máximo de conforto, segurança e eficácia.

O artigo intitulado "O estudo da aplicação da ergonomia aliada ao design no uso doméstico para o ato de passar roupa e seus utensílios", de Klafke et al. (2013), apresenta aspectos sobre o design aplicado a utensílios domésticos utilizados para passar roupa, fazendo um paralelo com os conceitos de ergonomia a fim de melhorar a execução da tarefa.

A partir de conceitos referentes à utilização dos objetos, procura-se adequar a utilização destes, priorizando a qualidade de vida e destacando a forma correta de sua utilização, para que não ocorram eventuais acidentes ou dores localizadas em regiões corporais que mais atuam na realização da tarefa. Esta análise apresenta um breve panorama entre o real modo de utilização e o modo como a tarefa deveria ser desenvolvida, pensando principalmente na qualidade de vida física do usuário (KLAFKE et al., 2013).

Na figura 1, demonstram-se as medidas padrão utilizadas nas mesas existentes no mercado. 
Figura 1 - Medidas mesa padrão, utilizadas nas mesas existentes no mercado atual.

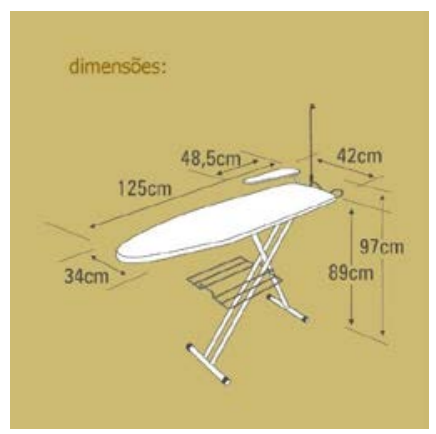

Fonte: Preciolândia (2014).

Devido à ausência específica de medidas antropométricas referentes a mesas de passar roupas, utilizou-se como base a medida para bancadas aplicadas por Panero e Zelnik (2002) (Figura 2).

Figura 2 - A) Bancada, utilizadas para trabalhos domésticos, industriais, residências e até mesmo em locais públicos. B) Alcance máximo da mão, analisadas as dimensões humanas e seus movimentos habituais.

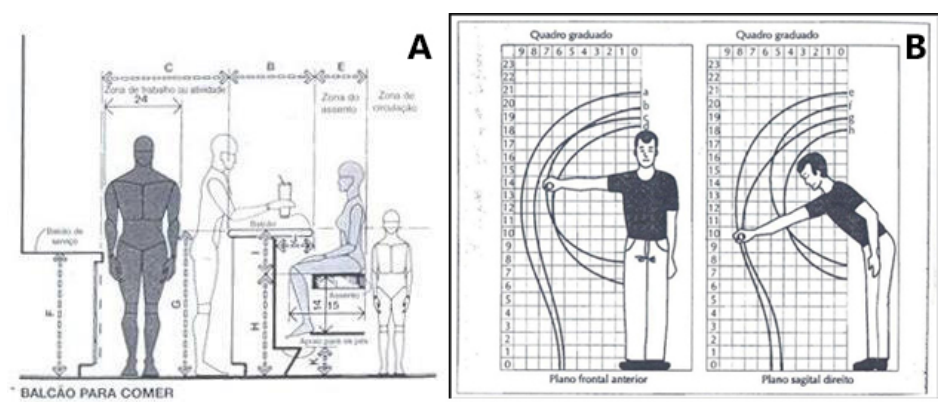

Fonte: Panero e Zelnik (2002).

A utilização das medidas ergonômicas indicadas como adequadas nas bibliografias estudadas, aplicadas ao novo produto, garante maior conforto ao usuário quando executar a tarefa de passar roupas porque respeita as necessidades que as pessoas possuem, a fim de minimizar seu desgaste físico e mental, proporcionandoIhes melhor qualidade vida e evitando a fadiga e o cansaço.

\section{ERGONOMIA E LER}

A preocupação com a eficácia da ergonomia, ao se desenvolver um projeto, diz respeito à preocupação que se deve ter com o conforto e o bem-estar do usuário, porque é através desse estudo que se adquirem informações específicas sobre como o usuário utilizará o produto final e sobre a possibilidade de este produto colaborar positivamente para a melhoria de sua qualidade de vida.

Este projeto tem como uma de suas principais funções a facilidade no manuseio do produto pelo usuário, considerando a altura ideal da mesa de passar, a qual será determinada analisando-se a altura média ideal para usuários femininos e masculinos. Este estudo sobre o ato de passar roupas abrange muito mais do que a análise do ato 
propriamente dito, abrange também as desvantagens de executar de maneira inadequada a tarefa, o que pode, segundo o Ministério da Saúde (2009), causar lesões por esforços repetitivos (LER).

De acordo com Varella (2014):

L.E.R. (Lesões por Esforço Repetitivo) não é propriamente uma doença. É uma síndrome constituída por um grupo de doenças tendinite, tenossinovite, bursite, epicondilite, síndrome do túnel do carpo, dedo em gatilho, síndrome do desfiladeiro torácico, síndrome do pronador redondo, mialgias -, que afeta músculos, nervos e tendões dos membros superiores principalmente, e sobrecarrega o sistema musculoesquelético. Esse distúrbio provoca dor e inflamação e pode alterar a capacidade funcional da região comprometida. A prevalência é maior no sexo feminino.

Para Victoriano (2013), o ideal, para economizar energia, é acumular o máximo de peças e passá-las de uma vez só. Porém, se, por um lado, isso é economicamente vantajoso; por outro, pode causar LER, pois o tempo de exposição ao esforço é maior (Figura 3).

Figura 3 - Esforços repetitivos no ato de passar roupas, seus desgastes e movimentos comuns causadores de lesões por esforços repetitivos.

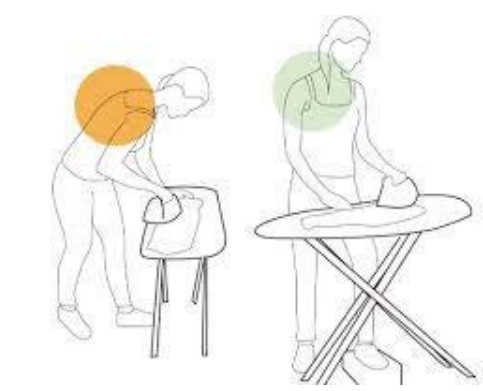

Fonte: Mais Saúde (2014).

Portanto, é importante considerar o tempo de exposição ao desgaste físico e ao esforço repetitivo durante a tarefa de passar roupas. Muitas vezes, acumular um número elevado de peças para passar e economizar energia pode resultar em consequências desvantajosas para a saúde do usuário, causando lesões e fraturas que poderiam ser evitadas com atividades adequadas em locais apropriados para execução desse trabalho doméstico.

\section{ASPECTOS SOCIOLÓGICOS}

O ato de passar roupas, como já visto anteriormente, pode causar transtornos físicos e emocionais às pessoas. Desse modo, uma análise feita com a sociedade atual foi considerada necessária para entender de que maneira um novo produto poderia trazer melhor qualidade de vida aos usuários deste produto. Assim, foi por meio do conhecimento do contexto social do público-alvo de determinado produto que se descobriram quais as necessidades existentes no mercado e quais os principais 
aspectos que deveriam ser considerados essenciais para afetar positivamente a vida desse público.

A rotina diária dos indivíduos é atingida diretamente dentro e fora de casa pelas obrigações domésticas (com suas vantagens e desvantagens) e pela forma com que conseguem administrar as tarefas. Atualmente, com mudanças radicais nos direitos trabalhistas das empregadas domésticas, este trabalho vem sendo cada vez mais valorizado, transformando a vida das pessoas, sejam elas domésticas ou patrões. Devido ao reajuste salarial imposto pela Emenda Constitucional no 72 , de 2 de abril de 2013 (BRASIL, 2013), as pessoas estão preferindo diaristas ou, ainda, executando o trabalho por si mesmas, fazendo com que o serviço doméstico, que antes era direcionado geralmente à apenas um empregado, seja dividido entre as pessoas da própria família.

Apesar de habitualmente se mandar para a lavanderia ternos, peças com enchimentos, vestidos bordados ou com detalhes em pedras, além de volumes grandes, como edredons e cortinas, passar roupas em casa é uma alternativa mais econômica, pois, ainda, que se pague diaristas para passar as roupas menores, o valor gasto é inferior ao de contratar serviços de lavanderia para todas as peças.

Segundo Pinheiro (2011 apud CARNEIRO, 2011), do Instituto de Pesquisa Econômica Aplicada (Ipea), "as classes média e média alta se organizaram em função do trabalhador doméstico, que estrutura suas vidas e possibilita suas jornadas de trabalho". Ainda conforme Pinheiro (2011 apud CARNEIRO, 2011), "famílias acostumadas à ajuda doméstica terão que encontrar novas maneiras de dar conta de cuidados com filhos, limpeza e alimentação", tendo de "adotar uma divisão de tarefas mais equilibrada entre homens e mulheres. Mas também o Estado será chamado à responsabilidade", a fim de preencher lacunas que estão sendo compensadas por trabalhadoras domésticas. Isso demonstra que o Brasil está valorizando a mão de obra e, desse modo, será preciso aumentar o valor do serviço terceirizado ou aplicar uma divisão justa de trabalhos domésticos entre os integrantes familiares.

Com a valorização do trabalho das empregadas domésticas, propiciada pelas mudanças que entraram em vigor, muitas famílias têm se esforçado para manter a organização de suas casas alternando-se entre si para fazerem as atividades domésticas, evitando, assim, o gasto com serviço terceirizado. Desse modo, é importante o uso de produtos que facilitem o dia a dia dessas famílias nas tarefas domésticas, como, no caso deste projeto, uma mesa de passar roupa adequada, que proporcione maior conforto e praticidade.

A ideia de uma mesa de passar roupas com melhorias ergonômicas e com proporções adequadas surgiu a fim de minimizar o desgaste físico e mental do usuário, seja ele um integrante da própria família ou um empregado doméstico.

\section{DESIGN}

Sabe-se que o designer age como um observador que utiliza diferentes meios em busca de soluções para os problemas encontrados nos produtos existentes no mercado, tornando-se, muitas vezes, um formador de opinião ao propor mudanças e benefícios sociais. Este é o trabalho do designer: desenvolver produtos que se tornem essenciais na vida das pessoas, para que, mesmo que de maneira quase imperceptível, os usuários tornem-se dependentes desses produtos. 
O design ocupa um papel muito importante na vida das pessoas. Conforme Heskett (2002), essa importância se dá não apenas por que o design auxilia na composição de ambientes esteticamente agradáveis, mas, acima de tudo, por auxiliar a tornar confortáveis os ambientes, melhorando a qualidade de vida dos usuários, uma vez que é nesses ambientes que os usuários vivem a maior parte de seu tempo e convivem com suas famílias e seus amigos. Assim, percebe-se que o bem-estar e o conforto dos usuários é essencial para que suas vidas sejam bem vividas.

Para Löbach (2001), o design já não é mais um fator decorativo; passou a mudar opiniões e ideias em todos os seguimentos, gerando pensamentos novos e formando profissionais capazes de melhorar a qualidade de vida das pessoas, visto que integram a sociedade atual e têm as mesmas características de consumo, diferenciando-se pelo gosto pessoal e pelas suas necessidades, muitas vezes não satisfeitas, em relação aos produtos utilizados. Além disso, têm a rotina diária apressada, com pouco tempo disponível para se preocuparem consigo mesmos ou com as tarefas domésticas.

Buscar desenvolver um produto que seja adequado às suas funções e traga ao usuário satisfação em seu cotidiano foi fundamental para que este projeto alcançasse o resultado esperado. Visou-se, então, produzir um móvel específico para passar roupas, que fosse funcional e facilitasse a vida do usuário, preocupando-se com o espaço e o ambiente, que seria utilizado como um todo. Para tanto, fez-se necessário compreender a rotina do indivíduo que utilizará o produto e pensar sobre a maneira mais eficaz de melhorar sua qualidade de vida.

\section{METODOLOGIA}

Foram feitas algumas análises para a criação do produto; no caso, a análise do problema, da necessidade e da relação social, do mercado, da função, da morfologia e, por fim, da tarefa. Com base na metodologia proposta por Bernd Löbach (2001), desenvolveu-se a análise do problema, que observa e estuda a situação real do produto existente no mercado, seus defeitos e suas qualidades, coletando informações e realizando uma pesquisa direcionada a determinado público-alvo. Já a análise da necessidade é o estudo da carência existente no produto que dificulta o dia a dia do usuário. A análise da relação social é o modo com que o produto afeta a vida do usuário.

Para a análise de mercado, fez-se um comparativo entre os produtos similares e, na análise da função, priorizou-se a função principal do produto e, havendo, a secundária também foi analisada. A análise estrutural realiza um "raio- $X$ " do produto, seus materiais, as montagens e os acabamentos. Há, ainda, a análise da configuração, que estuda a morfologia do produto.

Quanto à análise da tarefa, que trata da relação do usuário com o produto, por meio de observações e análises, destacam-se dois aspectos importantes do desenvolvimento de um produto: a ergonomia e a antropometria. Na maioria dos casos, essa análise considera a observação do jeito com que as pessoas realizam determinadas tarefas, tirando, dessa observação, os elementos para desenvolver o projeto. Por fim, na análise fotográfica, que é a própria análise da tarefa, deve-se observar o tempo utilizado para a execução da tarefa. Para isso, foi utilizada como base a metodologia de Baxter (2000). 
Na definição do problema, esboçou-se o retrato do problema, chegando à sua clarificação, ou seja, ao consenso sobre a problemática, e à definição de objetivos. Esse foi o momento da descoberta das necessidades do usuário e da carência latente em relação aos produtos já existentes. Tornou-se transparente a percepção das necessidades e carências por meio dos problemas vivenciados no seu cotidiano.

Na sequência, foram geradas alternativas, isto é, desenhos de projetos das ideias que serviram de base para a escolha do projeto final. A alternativa escolhida foi aquela que correspondia às necessidades do público-alvo e ao ambiente proposto. Após a escolha, realizou-se a solução do problema: a materialização da alternativa escolhida.

\section{ALTERNATIVA ESCOLHIDA}

Por meio da pesquisa realizada previamente, foram geradas alternativas (Figura 4a), obedecendo os requisitos de projeto sugeridos pelos usuários entrevistados, chegando-se, então, à alternativa que melhor se adequou às necessidades destacadas por eles. Foram considerados importantes principalmente detalhes ergonômicos e funcionais, mas que, adaptados ao novo produto, não interferissem em seu conceito de contemporaneidade e sofisticação, podendo ser utilizado em vários ambientes (Figuras 4b 4c).

Figura 4-A) Desenho técnico, vistas e cortes com medidas desenvolvidas com o objetivo de melhor adaptação do homem ao trabalho. B) Render móvel aberto, detalhamento do móvel em estado de uso, possibilitando melhor entendimento de sua funcionalidade. C) Render móvel fechado, mobiliário compacto necessitando de pouco espaço para armazenamento.

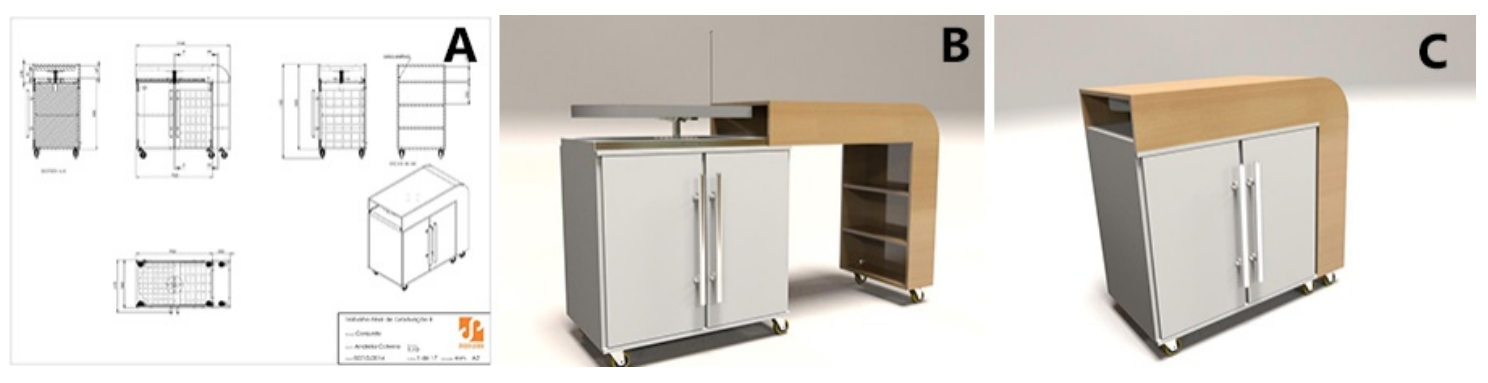

Fonte: Elaborado pela autora (2014).

\section{RESULTADOS E DISCUSSÃO}

Obtidas as informações na análise de mercado sobre mobiliário específico para passar roupas, poucas modificações têm se observado em relação a formas e funções que facilitem a vida dos usuários ao executar a tarefa de passar roupas. Em mesas encontradas na Europa, agregam-se valores que estão ainda fora da realidade da grande maioria das pessoas aqui no Brasil, visto que, nos países europeus, os usuários investem em eletrodomésticos com qualidade superior, uma vez que são motivados por não possuírem trabalhadores domésticos, sendo as pessoas da própria família que executam o trabalho.

Desse modo, a ideia de compor um ambiente residencial com uma mesa de passar que interaja com o restante do mobiliário trouxe ao usuário um móvel que, 
além de facilitar seu trabalho, proporciona-lhe utilizar um produto diferenciado pela sua forma e função.

\section{ASPECTOS ESTRUTURAIS}

O mobiliário foi produzido em MDF $18 \mathrm{~mm}$ porque além de não prejudicar o meio ambiente, já que se tratar de uma madeira transformada (Figura 5a), possui durabilidade e resistência, proporcionando ao usuário maior segurança ao executar a tarefa.

O produto possui um armário com divisória e cesto na parte interna e duas portas frontais com puxadores (Figura $5 b$ ) A tábua posiciona-se na parte superior do armário, conectada por uma rosca presa por parafusos e anéis de aço (Figura $5 c$ ), que facilita a regulagem de altura.

O armário é ligado por corrediças telescópicas a um tampo que, ao ser aberto, torna-se mesa de passar roupas e um móvel de apoio para auxiliar na tarefa. Este tampo possui uma prateleira embutida no lado direito do móvel. Na sua montagem, foram utilizados parafusos, roscas, pinos, corrediças telescópicas e anéis de aço.

Uma rosca produzida em aço, posicionada entre a tábua e o armário, foi fixada por parafusos e anéis. Esse mecanismo, além permitir o giro da tábua, também executa a regulagem da altura da mesa, a qual atinge a medida máxima de $1,10 \mathrm{~cm}$ e a mínima de $0,90 \mathrm{~cm}$.

Figura 5 - A) Estrutura.Produzida em MDF $18 \mathrm{~mm}$.. B) Render móvel parte interna, detalhamento dos compartimentos necessários para melhor organização e armazenamento. C) Render rosca aproximada, explicando o funcionamento do tampo giratório e a possibilidade de regulagem de altura do tampo.
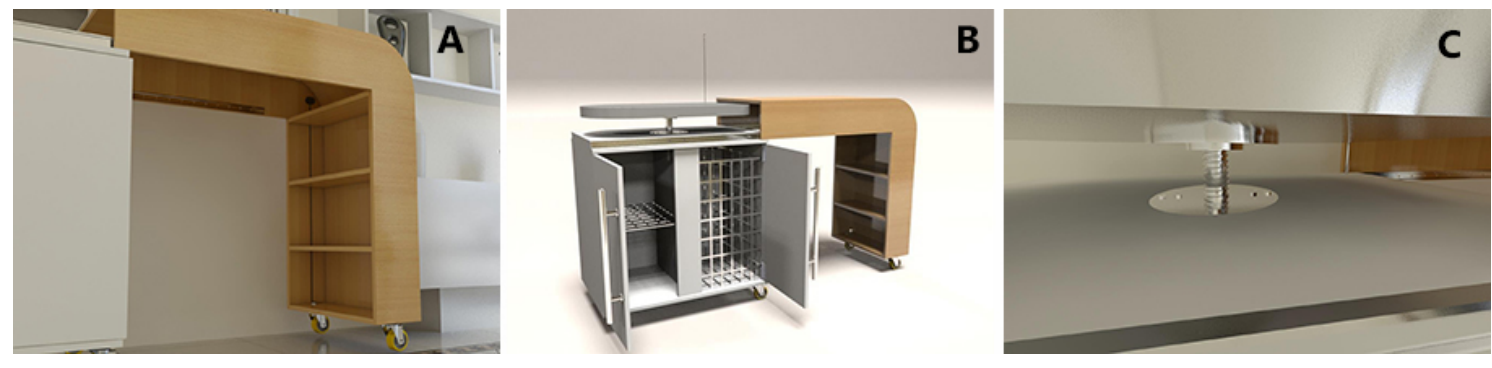

Fonte: Elaborado pela autora (2014).

\section{ASPECTOS FUNCIONAIS E ERGONÔMICOS}

O projeto obedeceu os critérios preestabelecidos com base no resultado do questionário realizado com o público-alvo para diagnosticar o problema e satisfazer as necessidades do usuário. Para isso, desenvolveu-se um tampo giratório para facilitar o uso da mesa também para pessoas canhotas, assim como foi aproveitado esse sistema de rosca giratória para regulagem de altura da mesa, adequando-se ergonomicamente e proporcionando maior conforto ao executar a atividade.

No tampo da mesa, utilizou-se tecido térmico, a fim de manter a temperatura da mesa, facilitando o trabalho e economizando energia elétrica, por manter o calor transmitido pelo ferro por mais tempo.

Foram utilizados cesto e prateleira aramados para melhor circulação de ar. Em sua base, foram utilizados rodízios com travas para facilitar a locomoção do móvel. 0 
tensor foi posicionado na mesa para evitar que o cabo elétrico atrapalhe a execução da tarefa e proporcionar maior segurança ao usuário, evitando que o ferro queime o cabo elétrico. Uma tomada fixada na mesa e um cabo elétrico que sai do móvel para se conectar à rede elétrica são inovações que fazem do projeto mesa de passar um produto adequado que proporcionará ao usuário, além de bem-estar e conforto, sua segurança.

A figura 6a ilustra o usuário executando a tarefa de passar roupas na mesa. Já as figuras $6 \mathrm{~b}$ e $6 \mathrm{c}$ ilustram o móvel interagindo com o ambiente.

Figura 6 -A) Render mesa sendo utilizada, demonstrando a utilização feita pelo usuário minimizando seu desgaste físico pela possibilidade de regulagem da altura ideal para execução do trabalho. B) Render mesa em uso no ambiente, demonstração do móvel sendo utilizado aberto, salientando sua

funcionalidade e praticidade. C) Render mesa fechada em ambiente, sendo demonstrada sua economia de espaço e utilidade ao armazenar objetos na parte interna e externa, sem interferir na decoração do espaço ocupado.

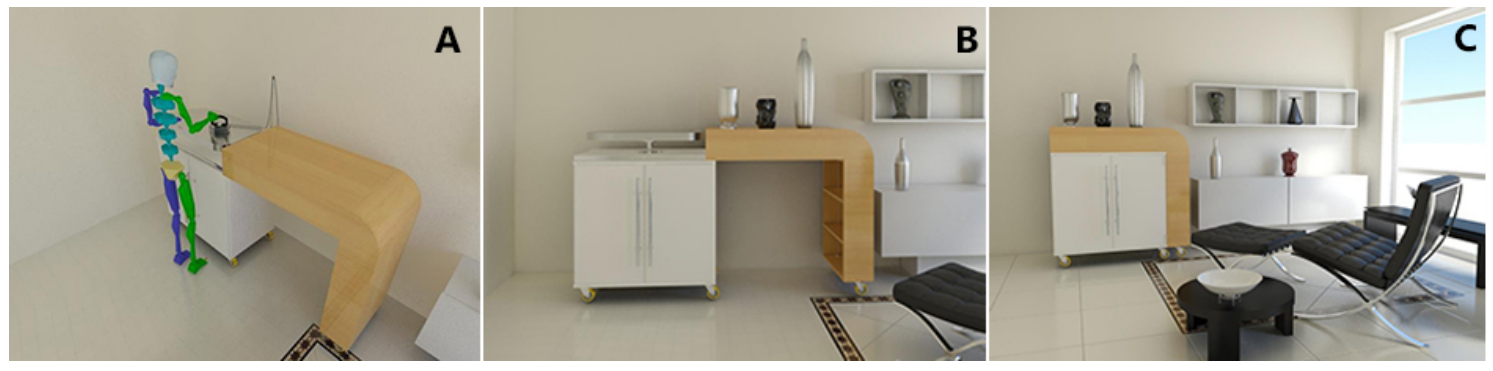

Fonte: Elaborado pela autora (2014).

O tampo giratório tem como principal função a regulagem da altura da mesa (Figura 7a). O uso de tecido térmico para forrar a tábua estofada com espuma (Figura 7b) facilita o trabalho do usuário por manter a temperatura do calor do ferro e distribui-la pela peça inteira, fazendo a execução da tarefa ser mais rápida, o que minimiza o desgaste sofrido pelo usuário.

Figura 7 - A) Render tampo da mesa, ocupado apenas quando a mesa estiver em uso, sem alterar a ocupação da mesma quando estiver fechada. B) Render superfície da mesa, revestida em tecido térmico, mantendo a temperatura da mesa em sua totalidade.
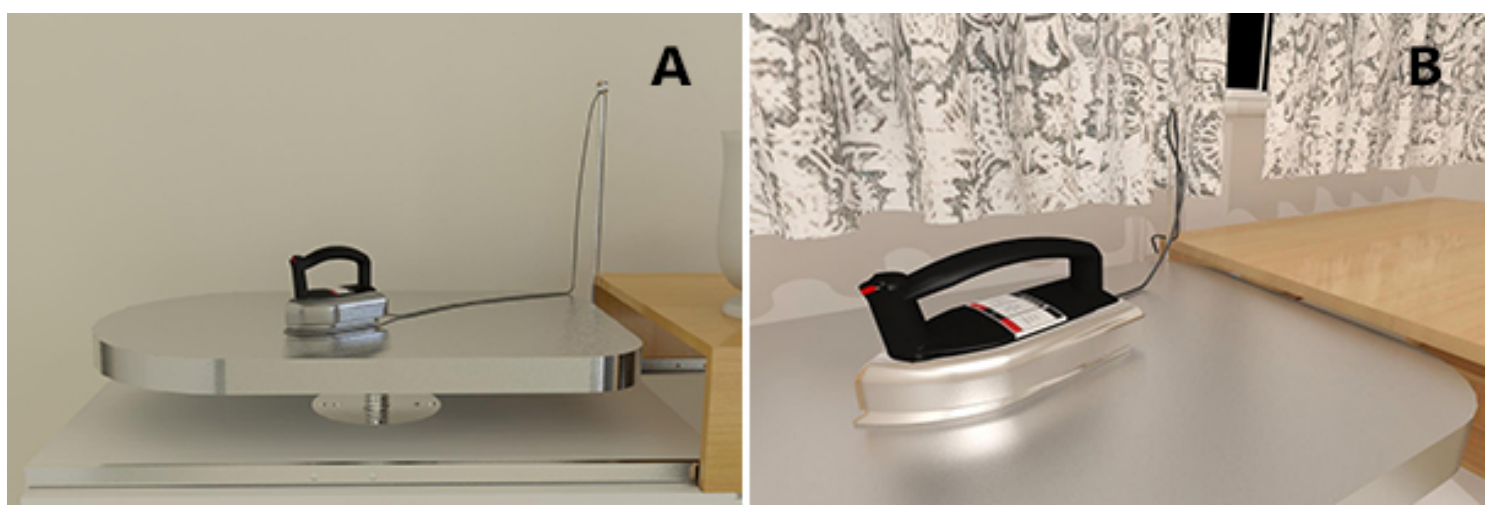

Fonte: Elaborado pela autora (2014). 
O cesto e a prateleira aramados, produzidos em aço inox, conforme ilustrado na figura 8a evitam o mofo e o mau cheiro das peças de roupas armazenadas dentro do armário. Há, ainda, na lateral do tampo, um compartimento produzido em MDF com prateleiras para armazenar produtos.

No entanto, os rodízios fabricados de silicone (Figura $8 b$ ) e fixados através de suporte e parafusos estão localizados na base do móvel. Quatro deles ficam posicionados no armário e outros dois na base do tampo curvado.

Figura 8-A) Render móvel aberto, demonstrando sua capacidade de organização de materiais e roupas, facilitando seu manuseio ao executar a tarefa. B) Render rodízios, facilitando o transporte do móvel e a melhor localização para execução da atividade.
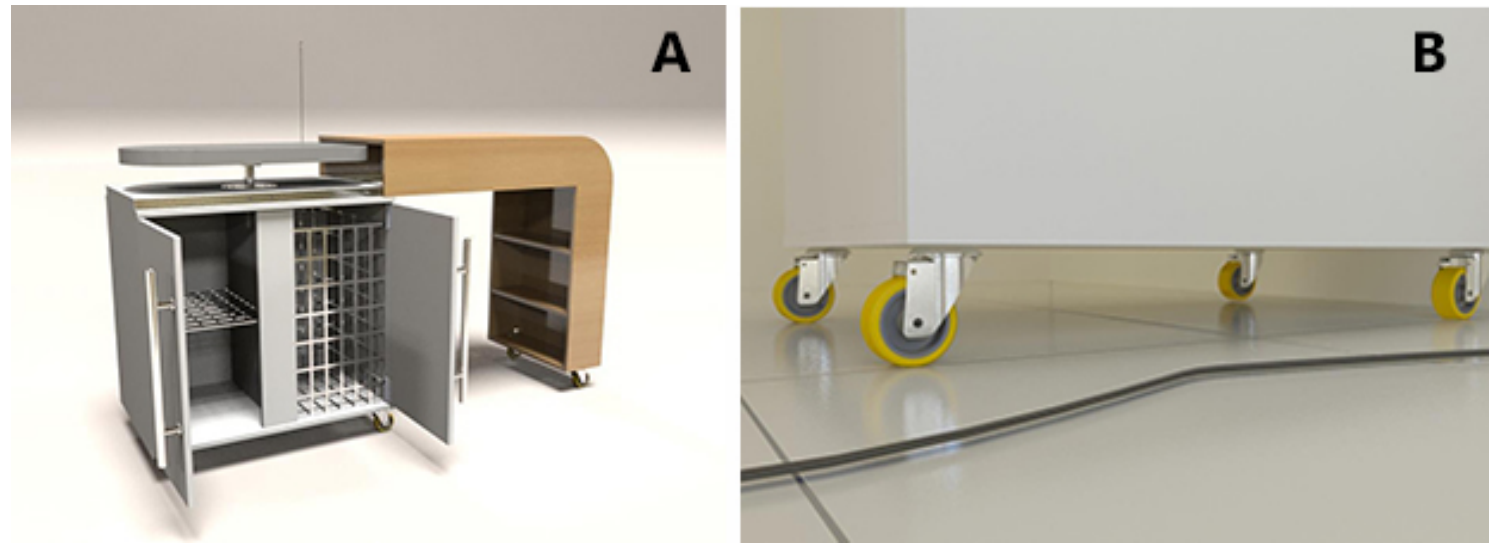

Fonte: Elaborado pela autora (2014).

A haste flexível foi produzida em aço e fixada por parafusos. Uma tomada foi posicionada no canto direito superior traseiro do tampo, facilitando o manuseio do ferro. Ainda, do móvel, sai um cabo elétrico posicionado no canto esquerdo inferior traseiro, conforme figura 9a. É possível o uso do tampo para utilização de outro equipamento que necessite de energia elétrica. O tampo da mesa, demonstrada na figura 9b, pode ficar fechado quando o móvel não estiver em uso.

Figura 9-A) Render haste, segurança ao usuário ao manusear o ferro de passar sem queimar o cabo elétrico. B) Render cabo elétrico, assegurando ao usuário maior extensão do cabo elétrico ao manusear o ferro e maior liberdade ao executar o trabalho.
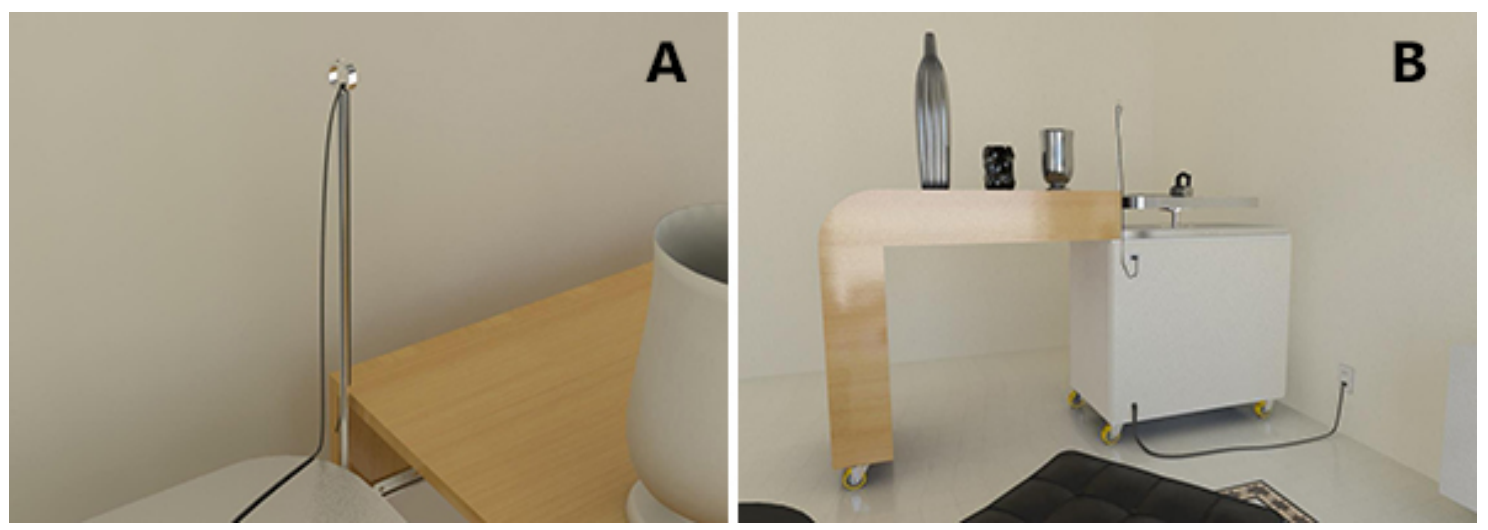

Fonte: Elaborado pela autora (2014). 


\section{CONCLUSÃO}

A pesquisa realizada previamente ao início deste trabalho constatou que o usuário que tem o hábito de passar roupas sofre desgastes tanto muscular como emocional, por se tratar de um esforço repetitivo e cansativo, que, muitas vezes, resulta em doenças causadas por esforços repetitivos (LER).

Isso se agrava ainda mais devido à maneira que o indivíduo realiza o trabalho, ou seja, acumulando peças para passar de uma vez só e economizar energia, o que leva a um esforço físico muito grande e, consequentemente, a problemas de saúde.

A ausência de um mobiliário específico e adequado ergonomicamente para a realização da tarefa, visto que as mesas existentes no mercado atual não possuem as regulagens de altura que satisfazem às necessidades do usuário, somado ao método inadequado da realização do trabalho, torna-se um grave problema no cotidiano das pessoas.

Portanto, desenvolveu-se um projeto que, além de sua forma inovadora e atual, interage com o mobiliário residenc, sendo dispensável um local específico para seu posicionamento, uma vez que possui um conceito orgânico e contemporâneo.

Quanto à saúde do usuário, a mesa possui opção de regulagem de altura, com fácil locomoção devido aos rodízios em sua base e à haste para suspender o cabo elétrico do ferro, evitando acidentes e proporcionando maior segurança ao usuário. Além disso, o projeto possui tomada embutida no próprio mobiliário para a conexão do ferro e um cabo elétrico saindo da mesa para conectar-se à rede, facilitando, dessa forma, a execução da atividade.

Assim, buscaram-se soluções de design que melhorassem a qualidade de vida do usuário, minimizando seus desgastes ao realizar a tarefa, proporcionando-lhe maior bem-estar e conforto e, ainda, compondo um ambiente com um móvel funcional e prático, mudando o dia a dia das pessoas que necessitam realizar esse trabalho.

\section{REFERÊNCIAS}

BAXTER, M. R. Projeto de produto: guia prático para o design de novos produtos. 2 ed. São Paulo: Blucher, 2000.

BRASIL. Emenda Constitucional no 72, de 2 de abril de 2013. Diário Oficial da União, Poder Legislativo. Brasília, DF, 3 abr. 2013. Disponível em:

<http://www.planalto.gov.br/ccivil_03/constituicao/Emendas/Emc/emc72.htm>.

Acesso em: 29 abr. 2014.

CARNEIRO, J. D. Escassez de domésticas pode mudar hábitos da classe média. 2011. Disponível em:

$<$ http://www.ipea.gov.br/portal/index.php?option=com_content\&view=article\&id=93 03\&Itemid=75>. Acesso em: 22 abr. 2014.

FALZON, P. Ergonomia. São Paulo: Blucher, 2007.

GOMES FILHO, J. Design do objeto: Bases Conceituais. Apresentação em Slides. 2003. Disponível em: <http://www.joaogomes.com.br/11-DESIGN-OBJETO-palestra-BC-estsimb-semiotica\%20ok.pdf>. Acesso em: 20 abr. 2014.

HESKETT, J. Design. São Paulo: Ática, 2002. 
KLAFKE, P. A. et al. Estudo da aplicação da ergonomia aliada ao design no uso doméstico para o ato de passar roupa e seus utensílios. In: CONGRESSO DE PESQUISA E EXTENSÃO DA FACULDADE DA SERRA GAÚCHA, 1., Caxias do Sul. Anais... Caxias do Sul: Faculdade da Serra Gaúcha, 2013. Disponível em:

<http://ojs.fsg.br/index.php/pesquisaextensao/article/viewFile/433/549>. Acesso em: 20 abr. 2014.

LIDA, I. Ergonomia Projeto e Produção. São Paulo: Edgard Blucher, 2005.

LÖBACH, B. Design Industrial: bases para a configuração dos produtos industriais. Rio de Janeiro: Edgard Blucher, 2001.

MAIS SAÚDE. 2014. Disponível em:

<http://juhbergerms.wordpress.com/category/postura-avaliacao/>. Acesso em: 22 abr. 2014.

MINISTÉRIO DA SAÚDE. Normas e Manuais Técnicos. Secretaria de Políticas de Saúde. Diagnóstico/tratamento/reabilitação/prevenção e fisiopatologia dos LER/DORT. Brasília, 2009.

PANERO, J.; ZELNICK, M. Dimensionamento para espaços interiores: um livro de consulta e referência para projetos. México: GG, 2002.

PRECIOLÂNDIA. 2014. Disponível em: <http://www.precolandia.com.br/>. Acesso em: 15 abr. 2014.

VARELLA, D. Lesões por esforço repetitivo. 2014. Disponível em: <http://drauziovarella.com.br/letras/l/lesoes-por-esforcos-repetitivos-l-e-r-d-o-r-t/>. Acesso em: 19 abr. 2014.

VICTORIANO, G. Passar roupa sem mistérios. 2013. Disponível em: $<$ http://www.portaldecoracao.com.br/decoracao/Portugues/detNoticia.php?codnotici $a=2315>$. Acesso em: 15 abr. 2014. 